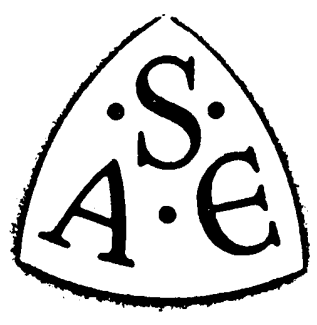

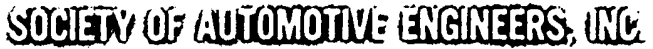

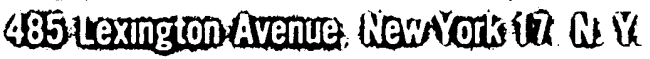

\title{
Philosophy of Value Analysis
}

\author{
L. D. Miles \\ General Electric Co.
}

\section{SOCUETV OF AUTOMOTIVE ENGUNEERS}

Automotive Engineering Congress Detroit, Mich. Jan. 14-18, 1963
$614 A$ 


\title{
Philosophy of Value Analysis
}

\author{
L. D. Miles \\ General Electric Co.
}

PHILOSOPHY is the body of general principles that provides a rational basis for understanding anything. We shall discuss here the general principles that fumish the rational basis for value analysis and we shall investigate the premises from which these principles have evolved.

What is back of the techniques of value analysis? What caused this organized approach to be developed in our economic system? What realities are responsible for creating the need for it? One word suffices to answer all three questions, namely, "costs."

Costs are the direct product of people and depend on their logic, attirudes and feelings, knowledge or lack of it, creativity or lack of it, and environment. To minimize cost, we must deal with the causes. To deal with the causes, the organized approach called "Techniques of Value Analysis and Engineering, " was created. I shall not discuss the techniques themselves but shall emphasize only the principles involved.

As related to his decision making, each engineer, manufacturing man, buyer, or manager is triply oriented:

1. He is a logical person.

2. He is a "feeling" person.

3. He is an environmentally influenced person.

\section{COSTS ARISE BECAUSE OF LOGIC AND FEELINGS}

The decisions of each person are the result of a compromise between logic and feeling. His immediate environment influences the compromise.

1. He believes a decision is right if in harmony with his logic.

2. He feels a decision is right if in harmony with his feelings.

3. He is content in his work and decisions if the decisions of his logic are in harmony with his feelings. He feels frustrated to the extent that his decisions must, for reasons of loyic, be made counter to his feelings.
Hence, he has a strong tendency to decide along lines of feeling without intense logical exploration, which might develop an opposite logic.

For example, consider the following sequence of events:

1. Product has failed in field repeatedly and the Company has been embarassed. It needs a different switch.

2. Engineer creatively develops one, using a new principle.

3. Manufacturing works out the way of making it, and $\$ 10,000$ in temporary tools are approved by management to try it.

4. It works. All feel pride before peers for successful accomplishment. Managers and immediate superiors feel and act in a commending manner. All are very pleased with job and selves; both logic and feelings are in total harmony.

5. Later (perhaps a year, perhaps five), competitive pressures require switch functions for lower cost, and the engineer is assigned the task because of his "experience "in the area. He knows more about it.

6. He attacks with vigor. Keeping the main operating principles of his former approach, he can change a few parts, improve some tooling, eliminate a few obvious uncontributing costs. He gets $20 \%$ out.

7. His logic says the changes are good. His feelings say the changes are fair. He has even now made some slight inroads into his earlier model, which was a proven success in the eyes of himself and his peers. His feelings don't like it. He is uncomfortable about it. He wishes it could have been left alone.

8. Now it becomes necessary to remove much more cost from the total product. He is asked, how much more can we, by pulling all the stops, get out?" His logic says, "a little." His feelings say, "none." He says, "possibly a hard maximum of $5 \%$."

If this engineer is to benefit the company's sales and eamings by a $50 \%$ reduction, he must have a new approach. Since the deterrent is his feelings, which have by now stop-

\section{ABSTRACT}

In simple terms value analysis may be thought of as the determination of the least cost to produce something that offers the most for your money and fulfills the function you expect of its But the means by which the determination is made is vastly more complex, the product of a philosophy not confined by statistical boundaries but operative in the more intangible areas of logic, knowledge, creativity, environment, and attitudes and feelings. In this paper the author explores the principles that constitute the rational basis of value analysis and relates their importance to reduction or elimination of costs. 
ped aggressive search by his logic, the solution must come through an approach that deals with his feelings.

Dr. Graves, eminent psychologist at Union College, tells us that logic does not change feelings, that feelings, being emotions, can be communicated with only in emotional terms. Therefore the approach created must emotionally communicate in order to release the man from his past publicly proven work and allow his feelings to become reorganized in a new situation that may remove one-half to three-quarters of the cost. This emotional approach must be based upon logic drawn from the task at hand so that the new adjustment of feelings will be such that the cost objectives are reached.

Now, at this point, a strong manager may say,

"I'li fix ri.at. I'll tell him that instead of $40 \%$ he must do it for 204 or he's fired. - Then the engineer will be emotionally involved. This may help, but unfortunately it runs afoui of another basic truism of the human: "What a man does no: jelieve credible, he is not motivated by." A good mal: will prchably quit, not wait to be fired from what he feels is an insossible siruation.

So, to de effective in aiding the individual to remove one-half or more of the cost, the approach must:

1. Be based upon the logic of the task.

2. Communicate emotionally.

3. Be credible to the individual.

Now our hard-headed business manager may say, "I'll short-cut all of that by assigning a competent man who has no past involvement with the situation to this task." In cost reduction, and for the reasons just made clear, this will actually produce much better results much faster. It will eliminate the necessity for emotionally communicating in credible terms with the men assigned.

The serious problems of this method, however, must be face d. Men just cannot and should not be abandoned like a used Kleenex after a good job has been accomplished. There are not usually equally challenging though different tasks that zan be exchanged between these good men. This nie_..ud, used sufficiently to get good results, may be decidediy disruptive to the organization, for in some types of work, continuity of certain types of experience may be almost necessary in order to assure undeviating quality.

It is therefore often very desirable in cost-oriented work to keep the same men in engineering and manufacturing and purchasing and to create an approach that will work in harmony with their nature, rather than counter to it, so as to ac'sieve reductions of cost of $50 \%$ or more without decrease in quaitity.

Thus the required compromise between logic and feeling maje .ecessary a planned approach that would communicate emotionally and credibly to individuals on the job so that body, mind, and spirit could be used to accomplish the drastically lower cost objectives. The esoteric will recognize this in the value analysis techniques.

bivitional communication is by case study and involvement. One of hundreds of case studies often used in teaching describes a quantity of one on which costs were reduced
90\%. A laboratory containing very large X-ray equipment for metal exploration was being built. To protect adjacent areas, technical men, included a partly encircling concrete wall in the specification drawings, according to their science, custom, and practice. It was $14 \mathrm{ft}$ high and $7 \mathrm{ft}$ thick. The best bid to construct it was $\$ 50,000$.

The manager of the entire plant asked the manager of the laboratory for a written guarantee that if he later moved the laboratory, he would "take the concrete with him." This he was reluctant to sign. The situation forced explora tion by constriction men who had no past involvement in radiation protection.

Their questions, "What is it for? What is its function? What else will accomplish that function?", brought the alternative of an earth wall into being. It cost one-tenth $(\$ 5000)$ of the best bid but was totally functional.

Although the objective result was the saving of $\$ 45,000$, was this an experience of logic or of emotions to the men involved? The answer is, "both" for the manager it was logic; to the construction men, logic and emotion; to the men who specified the original concrete, emotion; and to others to whom this story is told, emotion.

This type of case study communicates to feelings, prepares men to accomplish other results of a new higher magnitude.

Approaches and techniques must be created that will allow men to change their own feelings. They are included in the value analysis techniques.

But it is not enough for the whole man to "want" to operate at lower costs. How can he do it?

\section{COSTS ARISE BECAUSE OF KNOWIEDGE OR A LACK OF IT}

It has been said that if the decision maker, be he engineering, manufacturing, or purchasing, were in a room surrounded by all knowledge in the world that might bear upon his decision, then he would make the optimum decision. This is nonsense, since

1. He wouldn't know precisely what knowledge he needed.

2. He wouldn't find much of the information that was there.

3. He wouldn't get the needed combinations of knowledge from different sources usefully associated.

4. He would be just a little better off than the man usually is on the job (because the knowledge would be there, not 1000 miles away).

What is lacking? First, a better method for defining his problem in terms of exactly the knowledge he needs. Second, a system of search techniques that would bring up this knowledge when he needs it. Techniques must be, and are provided, in the value analysis system that will do both.

An example of the first is the extreme orientation to function, in customer's terms. What "function" does the customer want? Does he mean the terminal board, which he says he wants? No! Basically he wants only a suitable means for making connections. Already the knowledge needed has changed from "terminal boards" to "means of 
making electrical connections. " Does the customer want the spring that he says he wants? Nol Rather he is seeking a means for returning the shelf to a preferred position. Similarly, would he want the electronic gear he has specified? Nol The need is for something that will accomplish the function specified. An efficient system must send the decision maker searching for the knowledge he needs, not the knowledge he thinks he needs.

Men learning value analysis techniques have often fretted at the insistence on naming functions in two words and have often had animated discussions of a few hours' duration about exactly which two words best named the function the customer wants from an assembly or part. Later they would enthusiastically proclaim that although they still didn't agree on how to .lame it, they now "saw it in a different light," and ict ina searches for knowledge and use of creativity assuric. ...t e.:irely different orientation.

i. 1. i.ie:-i: system of techniques, after establishing preciseiy the ... is of knowledge needed, must include effective search techniques. Even if all needed knowledge were in one room, which it is not, an effective search system would be required.

Responding to this need, the value analysis system includes specific search techniques for reaching out into other local areas, other distant areas, other technical areas, other nontechnical areas, other industries, other areas of men's activity, efficiently to find the relevant knowledge. We have for two examples of one approach:

1. Use industry specialists to extend specialized knowledge.

2. Utilize and pay for vendors' skills and knowledge.

Bu: this is not enough, and the value analysis system is interced is fiil in the voids further with creativity.

\section{A BECAUSE OF CREATIVITY OR LACK OF IT}

Einsic:- said that when there is a problem to be solved, "Creativ : $:$. more important than knowledge."

To meer real life situations, the techniques of value analysis must

1. Provide logic.

2. Communicate emotionally in credible terms.

3. Provide new identity of knowledge needed.

4. Provide search techniques that will find that knowledge efficiently.

5. Eause creativity that will usefully combine the knowledge from diverse sources.

A chemical not yet compounded does not exist. A metal not yet developed does not exist. It's not because they couldn't be, but just because the required combination of creativity and knowledge have not yet been brought together. Similarly, an idea not "thought of" does not exist. The necessary combinations of creativity and knowledge have not yet been associated.

To accomplish the functions that the customer wants for h.31f o: a third of the historical or expected cost, a situation 12..no: ne created in which tho necessary creative ideation and essential knowledge are blended extensively and intensively. This is seen in the value analysis system by the strong and continuous emphasis on the skillful use of creativity throughout all parts of the job plan. More on this vital subject is not included here because it is well treated and documented by Osborn, VonFange, and others.

Still, creativity is not enough to complete the search and thus we turn to environment.

\section{COSTS ARISE BECAUSE OF ENVIRONMENT}

Of course few environments exist that would not accept a fully developed, fully debugged, fully tested, fully serviceproved change which would keep all customer factors at halfcost. But, significant improvements are not bom full grown. Resources, money, and men must be committed without assurance of results. Creative ideation, knowledge searches, exploration, and basic tests precede results. Of the creative ideation, $99 \%$ is worthless; $90 \%$ of the knowledge searches are useless: $75 \%$ of the basic tests fail. Meanwhile the designs and practices of the past are working perfectly, performance-wise.

Environment Unsafe - Hence there develops, to some extent in most environments, a "feeling" that men who press hard toward vastly better ways for accomplishing functions at lower cost are dreamers, and that they have in fact lost essential touch with reality and have their feet in the clouds and their heads out beyond thin air.

This takes the tangible form of occasional derision of the newest idea creations and especially of the continual stream of worthless ideas, useless knowledge, and failing tests.

The environment is often "unsafe " mentally and socially for activity that would produce large accomplishment. Only small, traditional-type cost reduction activities can comfortably live.

Environment Hazardous to the "New" - "Environment," as used here, includes the managers of a man, and his peers:

"Get out today's production; improve the process if you have time."

"Lick that engineering performance problem on the production line, develop a new approach later, if you have time."

"We made this change to save $\$ 8000$; it has already cost .us $\$ 25,000$ in field failures." But the ten changes that worked out well in the field, saving $\$ 300,000$, don't become conversation.

These are the pronouncements heard from management of the business. All communicate to the feelings of men. What do they say?

"He who sticks hard to the proven past, causing no unexpected problems, is without guile and a benefactor to his company. He who deviates from that proven present brings all manner of unexpected tragedies to his associates and company, and is without virtue."

To the extent that the "environment" in which men work is unsafe for the creative and hazardous for the new, all 
woris ::i decreasing costs is retarded or stopped. An efficient systi.: for ?reventing or reducing cost must, then, also deal ...setively with this environment. It must change it.

\section{STEPS OF VALUE ANALYSIS JOB PLAN}

To explore a few steps of the value analysis system and study the interface at which the system takes root from the general priaciples that constitute the philosophy, reference is made tu the value analysis job plan.

Step 1: Orientation - This step is starting the base of logic. It is framing the areas of knowledge that will later be pro . . .

S. istormation - In this step, the logic of the situatioii is :ompleted. The available knowledge is set in cieas $、$ icw. The framework of additional beneficial knowledge is broadened.

Sti, 3: $\therefore$ culation - Now, within the logic of this problem, presi:x know'edge and new knowledge are being creatively assriciated in new combinations. Often areas of kr. $1:$. . are creatively preassociated, showing that it will $\therefore \therefore \ldots . . \quad \therefore$ to search out and find the knowledge in the ..... . envity and knowledge are now both making their 2 ... ibutio:.

Kemainis. Steps - In the remaining steps of the job plan (analysis, program planning, and program execution) will be found a. invities tirat deal with the environment, communicare i..otionuily in credible terms, identify additional areas $: \ldots . .$. edge needed, and provide effective search.

\section{CONCLUSION}

What then, in conclusion, is the philosophy of value analysis? What are the general principles that fumish a rational basis for its system of techniques? The answers are contained in the following outline.

1. It is important to continuously reduce costs; that is, to increase continuously the amount of the function to the customer per unit of man's labor and nature's materials.

2. Since the amount of cost is the result of the decisions of people, a study of decision conditions is the starting point.

3. The decisions of people are controlled by their
(a) Logic.
(b) Attitudes or "feelings."
(c) Knowledge or lack of it.
(d) Creativity or lack of it.
(e) "Environment."

4. A system is needed that will:

(a) Take its logic from the task.

(b) Communicate emotionally in credible terms.

(c) Identify areas of knowledge needed.

(d) Provide efficient knowledge search.

(e) Integrate creativity effectively.

(f) Change environmental factors.

This, then, is the system of value analysis, the essential approach to costs reduction through understanding of function and coordination of man's emotional response with knowledge, creativity, and environment. 


\section{PHILOSOPHY OF VALUE ANALYSIS \\ Society of Automotive Engineers, Inc. \\ Detroit, Michigan \\ January 14,1963 \\ L. D. Miles}

My subject is "The Philosophy of Value Analysis".

Philosophy is understanding general principles which furnish a rational basis for anything. We will today work at understanding the general principles which furnish the rational basis for Value Analysis.

What is back of the techniques? What caused this organized approach to be developed in our economic system? What are the realities that caused the need?

$$
\begin{aligned}
& \text { Costs are because of people... } \\
& \ldots \text { their logic } \\
& \text {...their attitudes and feelings } \\
& \text {...their knowledge or lack of it } \\
& \text {...their creativity or lack of it } \\
& \text {...their environment. }
\end{aligned}
$$

To eliminate cost--deal with the causes.

To deal with the causes, was created the organized approach called, "The Techniques of Value Analysis and Engineering".

Of course, the techniques themselves are not my subject today.

As related to his decision making... each engineer, manufacturing man, buyer, manager is two persons...

He is a logical person. 
He is a "feeling" person.

He is also an environment influenced person.

Costs Are Because of Logic and Feelings

His decisions are the result of a compromise between the logic and the feeling. His immediate environment influences the compromise.

He believes a decision right if in harmony with his logic.

He feels a decision right if in harmony with his feelings.

He is content in his work and decisions if the decisions of his logic are in harmony with his feelings. He feels frustrated to the extent his decisions must, for reasons of logic, be made counter to his feelings.

Hence, a strong tendency to decide along lines of feeling--without intense logical exploration, which might develop an opposite logic.

For example...

Product has failed in field repeatedly.

Company has been embarrassed.

Need a different switch.

Engineer creatively develops one.

Uses a new principle.

Manufacturing works out way of making it.

$\$ 10,000$ in temporary tools approved by management to try it.

It works .

All feel pride before peers for successful accomplishment. 
Managers and immediate superiors feel and act in a commending manner.

All are very pleased with job and selves--both logic and feelings are in total harmony.

Later - perhaps a year - perhaps five, competitive pressures require switch functions for lower cost.

Engineer is assigned the task because of his "experience" in the area. He knows more about it.

He attacks with vigor.

Keeping the main operating principles of his former approach, he can change a few parts, improve some tooling, eliminate a few obvious uncontributing costs.

He gets $20 \%$ out.

His logic says the changes are good.

His feelings say the changes are fair.

He has even now made some slight inroads into his earlier model which was a proven success in the eyes of himself and his peers. His feelings don't like it. He is uncomfortable about it. He wishes it could have been left alone.

Now it becomes necessary to remove much more cost from the total product.

He is asked - how much more can we, by pulling all of the stops, get out?

His logic says -- a little.

His feelings say -- none.

He says - possibly a hard maximum of $5 \%$.

If he is to benefit the company's sales and earnings by a $50 \%$ reduction, he must have a new approach. 
Since the problem is - - his feelings -- which have by now stopped aggressive search by his logic, the solution must come by an approach which deals with his feelings.

Dr. Graves, eminent psychologist at Union College, tells us... ... that logic does not change feelings;

...that feelings, being emotions, can only be communicated with in emotional terms.

Therefore, an approach must be created which will emotionally communicate, in order to release the man from his past publicly-proven work and allow his feelings to become re-organized in a new situation which may remove onehalf to three-quarters of the cost.

This emotional approach must be based upon logic drawn from the task at hand so that the new adjustment of feelings will be such that the cost objectives are reached.

Now, at this point, a strong manager may say,

"I'll fix that. I'll tell him that instead of $40 \xi$ he must do it for $20 \%$ or he's fired." Then he will be emotionally involved--and this may help, but it has run afoul of another basic truism of the human. "What a man does not believe credible--he is not motivated by." A good man--will probably quit--not wait to be fired from what he feels is an impossible situation.

So, the approach, to be effective in aiding the individual to remove onehalf or more of the cost, must...

1 - be based upon the logic of the iask,

2 - communicate emotionally

3 - be credible to the individual 
Now our hard-headed business manager may say, "I'll short-cut all of that by assigning a competent man who has no past involvement with the situation to this task."

Actually in cost reduction, and for the reasons just made clear, this will produce much better results much faster. It will eliminate the necessity for emotionally communicating in credible terms with the men as signed.

The serious problems of this method, however, must be faced.

Men just cannot and should not be abandoned like a used kleenex after a good job has been accomplished, and there are not usually equally challenging though different tasks which can be exchanged between these good men.

This method, used sufficiently to get good results, may be decidedly dis ruptive to the organization.

In some types of work, continuity of certain types of experience may be almost necessary in order to as sure undeviating quality.

It is, therefore, in cost-oriented work, often very desirable to keep the same men in engineering and manufacturing and purchasing and to create an approach which will work in harmony with their nature rather than counter to it, still achieve reductions of cost of $50 \%$ or more without decrease in quality.

It was thus necessary to create a planned approach which would communicate emotionally and credibly to individuals on the job so that their full body, mind and spirit would be used to accomplish the drastically lower cost objectives. This, the esoteric will recognize in the Value Analysis techniques. Emotional communication is by case study and involvement. 
One of hundreds of case studies often used in teaching describes a quantity of one on which costs were reduced $90 \%$.

A laboratory containing very large $\mathrm{x}$-ray equipment for metal exploration was being built. To protect adjacent areas, technical men, according to their science, custom, and practice, included a partly encircling concrete wall in the specification drawings. It was $14^{\prime}$ high and $7^{\prime}$ thick. The best bid to construct it was $\$ 50,000$.

The manager of the entire plant asked the manager of the laboratory for a written guarantee that if he later moved the laboratory he would "take the concrete with him".

This he was reluctant to sign. The situation forced exploration by construction men who had no past involvement in radiation protection.

Their questions..."What is it for? What is its function? What else will accomplish that function?"...brought the alternative of an earth wall into being. It cost one-tenth- $\$ 5000--$ and was totally functional.

Although the objective result was the saving of $\$ 45,000--$ was this an experience of logic or of emotions to the men involved?

Both。

To the manager - logic.

To the construction men - logic and emotion.

To the men who specified the original concrete - emotion.

To others to whom this story is told - emotion.

This type of case study communicates to feelings, prepares men to accomplish other results of a new higher magnitude. 
Approaches and techniques must be created which will allow men to change their own feelings. They are included in the Value Analysis techniques.

But, it is not enough for the whole man to want to operate at lower costs-how can he do it?

Costs Are Because Of Knowledge - Or A Lack Of It.

It has been said that if the decision-maker - be he engineering, manufacturing, or purchasing - were in a room surrounded by all of the knowledge in the world which might bear upon his decision - then he would make the optimum decision.

\section{NONSENSE!}

He wouldn't know precisely what knowledge he needed.

He wouldn't find much of the information that was there.

He wouldn't get the needed combinations of knowledge from different sources usefully as sociated.

He would be just a little better off than the man usually is on the job because the knowledge would be there - not 1000 miles away.

What is lacking?

First, a better method for defining his problem in terms of exactly the knowledge he needs.

Second, a system of search techniques which will bring up this knowledge when he needs it.

Techniques must be, and are provided in the Value Analysis system which will do both.

An example of the first is the extreme orientation to function, in customer's terms. What "function" does he want? The terminal board which he says he 
wants? NOl...but rather a suitable means for making connections. Already the knowledge needed has changed from "terminal boards" to "means of making electrical connections". . The spring that he says he wants? NO!... rather a means for returning the shelf to a preferred position. . The electronic gear he has specified? NO! ...but rather something which will accomplish the function he needs. An efficient system must send him searching for the knowledge he needs--not the knowledge he thinks he needs.

Men learning the Value Analysis techniques have often fretted at the insist ence on naming functions in two words, have often had animated discussions of a few hours' duration on exactly which two words best named the function the customer wants from an assembly or part, only to later enthusiastically proclaim that although they still don't agree on how to name it they now "see it in a different light"--and that their searches for knowledge and use of creativity will have an entirely different orientation.

An efficient system of techniques, after establishing precisely the areas of knowledge needed, must include effective search techniques. Even if all needed knowledge were in one room, which it is not, an effective search system would be required.

Responding to this need, the Value Analysis system includes specific search techniques for reaching out--into other local areas, other distant areas, other technical areas, other non-technical areas, other industries, other areas of men's activity--to efficiently find the relevant knowledge. 
For two examples...

"Use industry specialists to extend specialized knowledge" and

"Utilize and pay for vendors' skills and knowledge".

Nor is that enough.

Costs Are Because Of Creativity - Or Lack Of It.

Einstein said - when there is a problem to be solved - "Creativity is more important than knowledge."

To meet real life situations, the techniques of Value Analysis must, not only...

1 - provide logic,

2 - communicate emotionally in credible terms,

3 - provide new identity of knowledge needed,

4 - provide search techniques which will find that knowledge efficiently; but also...

- cause creativity which will put the knowledge from diverse sources usefully together.

A chemical not yet compounded does not exist. A metal not yet developed does not exist... Not because it -- couldn't be -- but just because the required combination of creativity and knowledge have not yet been brought together.

Similarly, an idea - not "thought of" - does not exist. The necessary combinations of creativity and knowledge have not yet been associated.

To accomplish the functions which the customer wants for half or a third of the historical or expected cost, a situation must be created which will blend the necessary creative ideation and essential knowledge extensively and intensively. 
This is seen in the Value Analysis system by the strong and continuous emphasis on the skillful use of creativity throughout all of the parts of the job plan.

More on this vital subject is not included here because it is well treated and documented by Osborn, VonFange, and others.

Still, this is not enough.

Costs Are Because Of Environment.

Of course, few environments exist which would not accept a fully-developed, fully-de-bugged, fully-tested, fully-service-proven change which would keep all customer factors at half cost. But, significant improvements are not born full grown.

Resources - money - men must be committed without assurance of results. Creative ideation, knowledge searches, exploration, basic tests precede results. Ninety-nine percent of the creative ideation is worthless, ninety percent of the knowledge searches are useless, seventy-five percent of the basic tests fail. Meanwhile, the designs and practices of the past are working perfectly-performance-wise.

Environment Unsafe

Hence there develops, to some extent, in most environments, a "feeling" that men, pressing hard for vastly better ways for accomplishing functions at lower cost, are dreamers, have in fact lost essential touch with reality, have their feet in the clouds and their heads out beyond thin air. 
This takes the tangible form of occasional derision of the newest idea creations and especially of the continual stream of worthless ideas, useless knowledge and failing tests.

The environment is often "unsafe"--mentally and socially--for activity which would produce large accomplishment. Only small, traditional-type cost reduction activities can comfortably live.

Environment Hazardous To The "New"

"Environment", as here used, includes the managers of a man, and his peers.

"Get out today's production - improve the process if you have time."

"Lick that engineering performance problem on the production line, develop a new approach later - if you have time."

"We made this change to save $\$ 8000$ - it has already cost us $\$ 25,000$ in field failures." --The ten changes that worked out well in the field, saving $\$ 300,000$, don't become conversation.

These are the pronouncements which are heard from the men who are their contact with management of the business. They all communicate to the feelings of men. What do they say?

"He who sticks hard to the proven past causing no unexpected problems is without guile and a benefactor to his company. He who deviates from that proven present brings all manner of unexpected tragedies to his associates and company--and is without virtue."

To the extent that the "environment" in which men work is unsafe for the creative, and hazardous for the new, all work in decreasing costs is retarded or stopped. 
An efficient system for preventing or reducing cost must, then, also deal effectively with this environment. It must change it.

To explore a few steps of the Value Analysis system and study the interface at which the system takes root from the general principles which constitute the philosophy, reference is made to the Value Analysis Job Plan.

STEP 1

Orientation.

This step is starting the base of logic.

It is framing the areas of knowledge which will later be productive. STEP 2

Information.

In this step, the logic of the situation is completed.

The available knowledge is set in clear view.

The framework of additional beneficial knowledge is broadened.

\section{STEP 3}

Speculation.

Now, within the logic of this problem, present knowledge and new knowledge are being creatively as sociated in new combinations. Often areas of knowledge are creatively pre-associated showing that it will be beneficial to search out and find the knowledge in the areas. Creativity and knowledge are now both making their contribution. 
In the remaining steps of the Job Plan...

$$
\begin{aligned}
& \text { Analysis, } \\
& \text { Program Planning, } \\
& \text { Program Execution }
\end{aligned}
$$

... will be found activities which deal with the environment, communicate emotionally in credible terms, identify additional areas of knowledge needed and provide effective search.

What then, in conclusion, is the PHILOSOPHY OF VALUE ANALYSIS? What are the general principles which furnish a rational basis for its system of techniques?

1 - It is important to continuously reduce costs; i. e., to continuously increase the amount of the function to the customer per unit of man's labor and nature's materials.

2 - Since the amount of cost is the result of the decisions of people, a study of decision conditions is the starting point.

3 - The decisions of people are controlled by:
a - their logic
b - their attitudes or "feelings"
c - their knowledge or lack of it
d - their creativity or lack of it
e - their "environment" 
4 - A system is needed which...
a - takes its logic from the task
b - communicates emotionally in credible terms
c - identifies areas of knowledge needed
d - provides efficient knowledge search
e - integrates creativity effectively
f - changes environmental factors.

5 - That system is Value Analysis. 